\title{
Effects of Temporal Wind Patterns on the Value of Wind-Generated Electricity in California and the Northwest
}

\author{
Matthias Fripp and Ryan H. Wiser
}

\begin{abstract}
Wind power production is variable, but also has diurnal and seasonal patterns. These patterns differ between sites, potentially making electric power from some wind sites more valuable for meeting customer loads or selling in wholesale power markets. This paper investigates whether the timing of wind significantly affects the value of electricity from sites in California and the Northwestern United States. We use both measured and modeled wind data and estimate the time-varying value of wind power with both financial and load-based metrics. We find that the potential difference in wholesale market value between bettercorrelated and poorly correlated wind sites is modest, on the order of 5-10 percent. A load-based metric, power production during the top 10 percent of peak load hours, varies more strongly between sites, suggesting that the capacity value of different wind projects could vary by as much as $\mathbf{5 0}$ percent based on the timing of wind alone.
\end{abstract}

Index Terms - energy resources, power generation economics, renewable energy sources, wind power generation

\section{INTRODUCTION}

Wind power production varies on a diurnal and seasonal basis. In this paper, we use wind data from three different sources to assess the effects of wind timing on the value of electric power from potential wind farm locations in California and the Northwestern United States. By "value," we refer to either the contribution of wind power to meeting the electric system's peak loads, or the financial value of wind power in wholesale electricity markets.

Sites for wind power projects are often screened or compared based on the annual average power production that

Manuscript received October 16, 2006. The work described in this paper was funded by the Office of Energy Efficiency and Renewable Energy (Wind \& Hydropower Technologies Program) and by the Office of Electricity Delivery and Energy Reliability (Permitting, Siting and Analysis) of the U.S. Department of Energy under Contract No. DE-AC02-05CH11231. Portions of this paper were previously published in the Proceedings of the 26th USAEE/IAEE North American Conference, Ann Arbor, MI, Sept. 24-27, 2006.

M. Fripp is with the Energy and Resources Group, University of California, 310 Barrows Hall, Berkeley, CA 94720, USA (phone: 510-841-6822; email: mfripp@ berkeley.edu).

R. H. Wiser is with Ernest Orlando Lawrence Berkeley National Laboratory, 1 Cyclotron Road, MS 90R4000, Berkeley CA 94720-8136, USA (email: rhwiser@1bl.gov). would be expected from wind turbines at each site [1-6]. However, at many locations, variations in wind speeds during the day and year are correlated with variations in the electric power system's load and wholesale market prices [7-11]; this correlation may raise or lower the value of wind power generated at each location. A number of reports address this issue somewhat indirectly by studying the contribution of individual wind power sites to the reliability or economic operation of the electric grid, using hourly wind speed data [12-16]. However, we have not identified any study that examines the effect of variations in wind timing across a broad geographical area on the wholesale market value or capacity contribution of different wind power sites. We have done so, to determine whether it is important to consider wind timing when planning wind power development, and to try to identify locations where timing would have a more positive or negative effect.

In our research, we seek to answer three specific questions:

1) How large of an effect can the temporal variation of wind power have on the value of electric power from different wind resource areas?

2) Which locations are affected most positively or negatively by the seasonal and diurnal timing of wind speeds?

3) How compatible are wind resources in California and the Northwest (Washington, Oregon, Idaho, Montana and Wyoming) with wholesale power prices and loads in either region?

The latter question is motivated by the fact that wind power projects in the Northwest could sell their output into California (and vice versa), and that California has an aggressive renewable energy policy that may ultimately yield such imports.

We perform this assessment using three data sources: a numerical wind model, anemometer measurements, and historical power production at existing wind farms. Each of these is an imperfect estimator of turbine-height wind conditions - numerical models have limited resolution and mathematical detail, while anemometer and production data are available for limited time periods and only for heights lower than modern turbines. By comparing results from all three, we seek to draw firmer conclusions than we could from any one individually.

This paper summarizes results that are presented in more detail in a recent report from Lawrence Berkeley National Laboratory [17]. 


\section{METHODS}

\section{A. Wind Data}

We use three wind datasets to estimate the time-varying wind power available from California and Northwestern wind sites:

1) Modeled: AWS Truewind provided modeled wind speeds for every cell on a 200-meter grid in California and a 400-meter grid in the Northwest [18, 19]. This dataset was created by modeling weather conditions for 366 historical days, chosen at random from a 15-year period. AWS TrueWind provided average wind speeds for every month-hour combination in California (e.g., 4-5 $\mathrm{pm}$ in July) and every season-hour in the Northwest (e.g., 8-9 pm "winter": December, January and February).

2) Anemometers: We used hourly anemometer data from Kenetech, Inc. (167 sites, various periods in 1991-94) [20], the Bonneville Power Administration (6 sites, 1985-2003) [21] and the DOE Candidate Site program (7 sites, 1977-82) [20].

3) Actual Wind Farm Production: We used hourly power production data from the Altamont, Tehachapi and San Gorgonio wind resource areas in 2002 [22].

AWS TrueWind provided diurnal profiles of wind speeds that were averaged over months or seasons, because they believed that their modeled wind data were insufficient to report at a finer temporal resolution. Similar concerns arise in attempting to characterize electricity loads, market prices, and anemometer-based wind speeds from the few years of hourly measurements that are available. We consequently performed all of our analysis using wind speeds and electricity data that were averaged for each combination of month and hour (e.g., 6-7 p.m. in June) ${ }^{1}$, which we believe provides the most robust estimate possible of the "typical" seasonal and diurnal variation of wind speeds and electricity demand. This approach implicitly neglects any hour-to-hour correlation between wind speeds and electricity demand and prices, beyond the correlation captured by their month-hour or season-hour averages.

\section{B. Wind Resource Areas}

For some of the analysis that follows, we group the anemometers in our dataset into separate "wind resource areas," about $40 \mathrm{~km}$ across, in order to estimate the local effects of wind timing in the areas that are most likely to receive wind power development. These areas are shown in Fig. 1.

\section{Electric Power Production from Wond}

We perform several steps to estimate average wind power production for each month-hour combination from the modeled and anemometer datasets.

\footnotetext{
${ }^{1}$ As noted above, the modeled hourly data for the Northwest were only available on a seasonal basis. When using this dataset, we assumed that speeds were the same for all three months in each season.
}

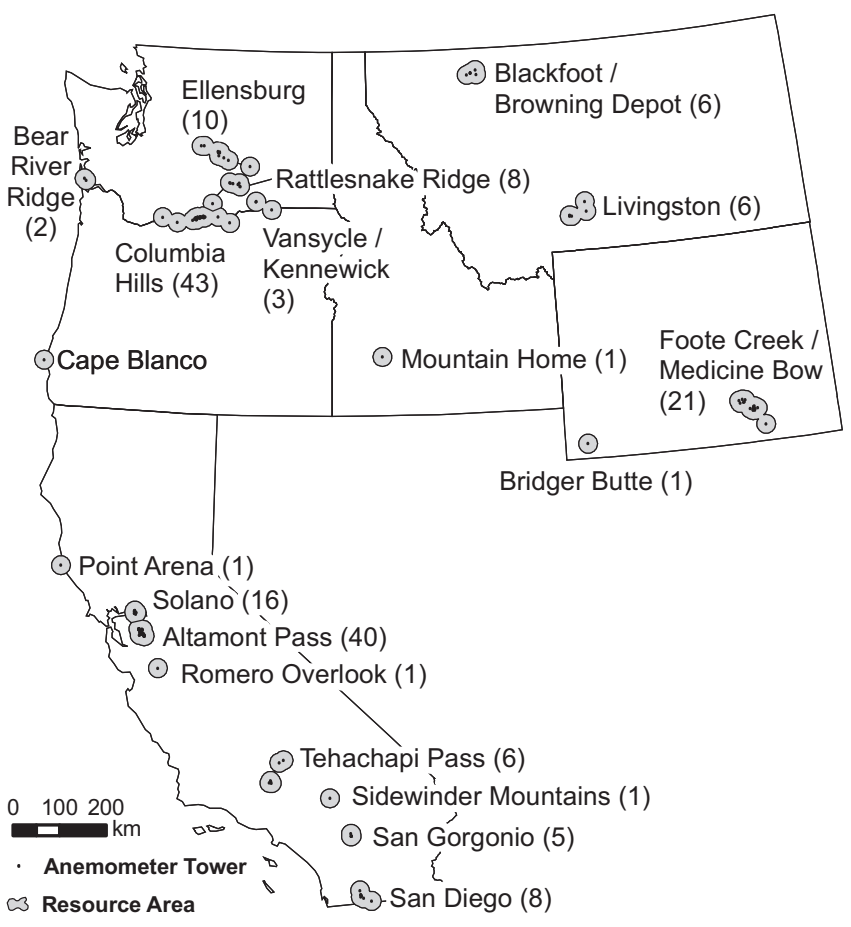

Fig. 1. Locations of anemometers and wind resource areas. Parentheses indicate the number of anemometer towers in each area.

All the measurements of wind speeds in our anemometer dataset were taken at levels below the hub height of modern wind turbines. The modeled data for the Northwest were also calculated at a relatively low height. We estimate wind speeds at a turbine hub height of 70 meters above ground level by applying a power law adjustment to the lower-level wind speed:

$v_{h}=v_{h_{0}}\left(h / h_{0}\right)^{\alpha}$,

where $h$ is the turbine height (70 meters), $h_{0}$ is the height for which the wind speed is known, $v_{h}$ and $v_{h_{0}}$ are the wind speeds at these heights, and $\alpha$ is a "wind shear exponent." After a review of time-varying wind speeds at different heights in our anemometer dataset and in other reports, we adopted wind shear exponents of $\alpha=0.09$ during the day and $\alpha=0.20$ at night [17].

The typical air density for each month-hour combination at each location is calculated from the elevation above sea level and the average temperature for that month and hour. We calculate air density $(\rho)$ using the equation

$\rho=\frac{\rho_{0}}{R_{d}(T+\beta z)}\left(1+\frac{\beta z}{T}\right)^{1-\frac{g}{R_{d} \beta}}$,

where $\rho_{0}$ is the density of air at standard temperature and pressure $\left(1.225 \mathrm{~kg} / \mathrm{m}^{3}\right), R_{d}$ is the gas constant for dry air, $\mathrm{T}$ is the local temperature $\left({ }^{\circ} \mathrm{K}\right), \beta$ is the temperature lapse rate for the standard atmosphere $\left(6.5^{\circ} \mathrm{C} / \mathrm{km}\right), z$ is the elevation of the turbine above sea level, and $g$ is the force of gravity.

Next, we use the manufacturer's power curve for a GE Energy 1.5 MW wind turbine to calculate the potential power production at each location during each time period. We chose 
this turbine because it made up the majority of new U.S. wind capacity in 2005-06 [23]. For consistency, we assume a 70.5 meter rotor (model 1.5s) is used at all locations. This turbine converts about 40 percent of the kinetic energy of wind into electric power at wind speeds between $4 \mathrm{~m} / \mathrm{s}$ and $13 \mathrm{~m} / \mathrm{s}$, and tops out at $1.5 \mathrm{MW}$ for speeds from $13 \mathrm{~m} / \mathrm{s}$ to $25 \mathrm{~m} / \mathrm{s}$.

Finally, we assume that a total of 12 percent of the power that could potentially be produced by each turbine is lost, due to electrical and control system losses, blade contamination, weather (icing, lightning, etc.), wake effects, turbulence, and turbine outages [24].

For each anemometer location, the average power production $\left(P_{m, h}\right)$ for the combination of month $m$ and hour $h$ is calculated as

$$
P_{m, h}=(1-0.12) \frac{1}{\operatorname{count}\left(T_{m, h}\right)} \sum_{t \in T_{m, h}} \mathrm{P}\left(v_{t}, \rho_{m, h}\right),
$$

where $T_{m, h}$ is the set of all measurement hours that correspond to month $m$ and hour $h, v_{t}$ is the height-adjusted wind speed during hour $t, \rho_{m, h}$ is the typical air density at that location during this month and hour, and $\mathrm{P}(v, \rho)$ is the power curve for the GE $1.5 \mathrm{~s}$ turbine.

For the modeled data, the power production at each grid cell during each month-hour is calculated as

$$
P_{m, h}=(1-0.12) \int_{0 \mathrm{~m} / \mathrm{s}}^{25 \mathrm{~m} / \mathrm{s}} \mathrm{f}_{m, h}(v) \mathrm{P}\left(v, \rho_{m, h}\right) d v,
$$

where $\mathrm{f}_{m, h}(v)$ is a probability density function for the wind speed at that location and time (a Weibull function derived from the modeled data) and $\mathrm{P}(v, \rho)$ is the turbine power curve. The integral averages across all the operable speeds of the GE $1.5 \mathrm{~s}$ turbine [17].

\section{Value of Wind Power}

We compare the wind data to electricity loads and wholesale electricity prices for California and the Northwest to estimate the effects of wind timing on the value of wind-generated electricity. The effects of timing were measured by two approaches.

\section{1) Capacity Value}

Electric generators, such as wind turbines, can contribute both energy and capacity to the electric power system. The energy contribution is simply the total amount of usable energy supplied by the generator per year, regardless of the time when it is produced. The capacity contribution is most often defined as the number of watts by which the system's yearround loads can be increased after a generator is added to the system, without increasing the chance of a shortfall in electric supply over the course of the year [12-14]. This "effective load-carrying capacity" (ELCC) depends on the reliability and timing of both the new generator and the other generators already in the system, as well as the timing of the electric load.

Power system planners must ensure that their system has an
TABLE I

PEAK LOAD HOURS IN CALIFORNIA AND THE NORTHWEST (2000-04)

\begin{tabular}{ll}
\hline \hline California & Northwest \\
\hline June, 14:00-17:00 & June, 15:00-17:00 \\
July, 11:00-21:00 & November, 17:00-19:00 \\
August, 11:00-21:00 & December, 07:00-11:00, 16:00-21:00 \\
September, 13:00-19:00 & January, 07:00-12:00, 16:00-21:00 \\
& February, 07:00-10:00, 17:00-20:00 \\
\hline \hline
\end{tabular}

adequate supply of both energy and capacity each year. ${ }^{2}$ Because wind power generators are intermittent and nondispatchable, concerns are often raised about how much capacity they will contribute to the power system.

A formal ELCC analysis requires detailed, proprietary data about the power system, as well as extensive computation for each additional generator to be added. To reduce these requirements, a number of simplified estimators of ELCC have been developed. These generally focus on the capacity factor ${ }^{3}$ of the generator during the specific historical hours with the greatest risk of power shortfall, or, similarly, during the historical hours with the highest electricity loads [26, 27]. Such approaches allow rapid comparison of the capacity value of different projects, and are increasingly being used by system planners to assess resource adequacy [26-30]. For example, the PJM Regional Transmission Organization assigns a capacity credit to wind farms based on their average power production from 3 to $7 \mathrm{pm}$ in June-August [27], and California assigns a capacity credit to generators each month based on their performance from 12 to $6 \mathrm{pm}$ during that month of the previous three years [30].

For this study, we have adopted one of the most common approximations to ELCC, which we call the "peak-hours capacity factor." This is calculated as the capacity factor of the wind power plant during the 10 percent of hours of the year when the power system has the highest electricity loads. This measure is similar in nature to the regulatory approaches mentioned above, but is likely to be a more accurate estimate of the true capacity contribution of a wind project, because it emphasizes the specific hours when the power system faces the greatest risk of shortfall [27]. In many cases it can be within a few percentage points of the true ELCC [13, 26, 31].

We calculate historical electricity loads for both California and the Northwest as the total load reported in FERC Form 714 filings by all electric control areas within each region for each hour for 2000 through 2004 [32]. Since our analysis is performed for each of the 288 month-hour combinations in the year, we estimate the capacity factor at each grid cell during the 29 month-hours when electricity demand was highest. Table I shows when these 29 hours occurred for California and the Northwest. Historically, loads in California have peaked on

\footnotetext{
${ }^{2}$ The Northwest has historically been more constrained by energy supply in its hydro system than by capacity shortfalls in peak hours. However, capacity reserve margins in the Northwest are decreasing [25], and the capacity contribution of new generators may soon be a significant concern there, as it already is in California.

${ }^{3}$ Capacity factor is a normalized measure of the power production from a generator. For any time period, it is defined as the ratio of average power production to the maximum possible power output for that generator.
} 
summer afternoons, and loads in the Northwest have peaked predominantly on winter mornings and evenings.

In this paper, we summarize the effect of wind timing on the peak-hours capacity factor at each site, using a variable $f_{c}$. For each site, $f_{c}$ shows the fractional difference between the peakhours capacity factor $\left(c_{\text {peak }}\right)$ and the annual average capacity factor $\left(c_{\text {year }}\right)$ :

$f_{c}=\frac{c_{\text {peak }}-c_{\text {year }}}{c_{\text {year }}}=\frac{c_{\text {peak }}}{c_{\text {year }}}-1$,

That is, $f_{c}$ shows the fraction by which the peak-hours capacity factor is increased or decreased by wind timing. A wind site with a positive value of $f_{c}$ would have higher average power production during peak load hours than during the year as a whole, suggesting that its capacity contribution would be larger than that of a flat block of power with the same annual energy value. A negative value of $f_{c}$ indicates the reverse.

\section{2) Wholesale Market Value}

Many studies have investigated the cost of using conventional generators to compensate for the intermittency of wind power over short time periods - maintaining grid stability over periods of seconds, minutes or hours [33-36]. Generally, it is found that these variations can be managed at a cost of about 10 percent of the value of the wind power [33].

For our study, we neglect these short-term variations, and take a longer-term approach, investigating the effect of persistent patterns of wind timing on the financial value of wind power. For example, if a wind project typically delivers more power when wholesale electric prices are high, it could be more valuable than one which usually delivers power when those prices are low.

To investigate this, we compare the wholesale market value of wind under two scenarios: one in which wind production does not vary with time, and another in which it does. In both cases, wind plants are assumed to be "price takers" in timevarying wholesale markets. In reality, wind farm developers typically arrange long-term power sales agreements rather than selling power in the wholesale market; however, this technique gives a simple estimate of the value of power from each location, relative to a flat block of power. To the extent that longterm and short-term markets tend to balance, these estimates may also give some information about the real revenues available to wind farm developers at each location.

Wholesale prices rise and fall in response to scarcity of either generating capacity or energy, so, unlike the peak-hours capacity factor discussed earlier, the wholesale market value reflects, to some degree at least, the combined contribution of both capacity and energy from a wind project.

For each wind site, we first estimate the annual market value that would be expected based on time-varying wind speeds and wholesale power prices:

$v_{v a r}=\sum_{m=1}^{12} \sum_{h=1}^{24} d_{m} P_{m, h} p_{m, h}$.

Here $P_{m, h}$ is the power production expected at the location during each month $m$ and hour $h, p_{m, h}$ is the average wholesale market price of power in the region during the same time period, and $d_{m}$ is the number of days in the month. For sites in California, we use historical wholesale prices $\left(p_{m, h}\right)$ that are the average of the CalPX prices for the NP15 and SP15 hubs for each month-hour combination during July 1998 - June 1999. We chose this time period because it provides a full year of market data before the power crisis of 2000-01 and the subsequent restriction of wholesale markets. For Northwestern sites, month-hour average prices are based on the Dow Jones hourly prices for the Mid-C hub for May 2002 - April 2005 [37]. We have also performed this analysis using forecast prices for both regions [17]; results were similar to those found using historical prices, and are omitted from this paper for brevity.

We next estimate the annual market value for wind power from each location if production were invariant with time:

$v_{i n v}=\sum_{m=1}^{12} \sum_{h=1}^{24} d_{m} \bar{P} p_{m, h}$,

where

$\bar{P}=\frac{1}{8760} \sum_{m=1}^{12} \sum_{h=1}^{24} d_{m} P_{m, h}$

is the annual average power production at that location and other terms are the same as in (6). This is the market value that would be achieved by a turbine with unvarying year-round power output, or power output that varies independently of market prices.

Finally, for each site we compute $f_{v}$, the fractional difference between the market value of power with time-varying winds, and the value that would be expected if winds were invariant.

$f_{v}=\frac{v_{\mathrm{var}}-v_{i n v}}{v_{i n v}}=\frac{v_{\mathrm{var}}}{v_{i n v}}-1$,

This measure indicates the degree to which temporal wind patterns would be expected to increase or decrease the wholesale market value of wind power from each site.

\section{E. Limitations of this Analysis}

This study is designed to assess the value of small incremental additions of wind power to the electric grid. This assumption simplifies our analysis, but introduces limitations which could be relaxed in future work.

First, we assume that new wind power does not shift the timing of wholesale power prices or peak residual loads. In reality, if large amounts of wind power are added to the system, they may cause the value of power to fall at the times when the most wind power is available, so that the timing of wind has a more negative effect than shown here.

Second, in order to use a common standard to compare the value of power from different wind sites, we assume that sufficient transmission capacity is available to deliver power from each wind site to other locations throughout the region. We then aggregate electric loads across all utility service areas to determine a single set of peak load hours for each region. Similarly, we use the market prices of electricity at one major load center in California and one in the Northwest. These generalizations allow for direct comparison of wind power from 

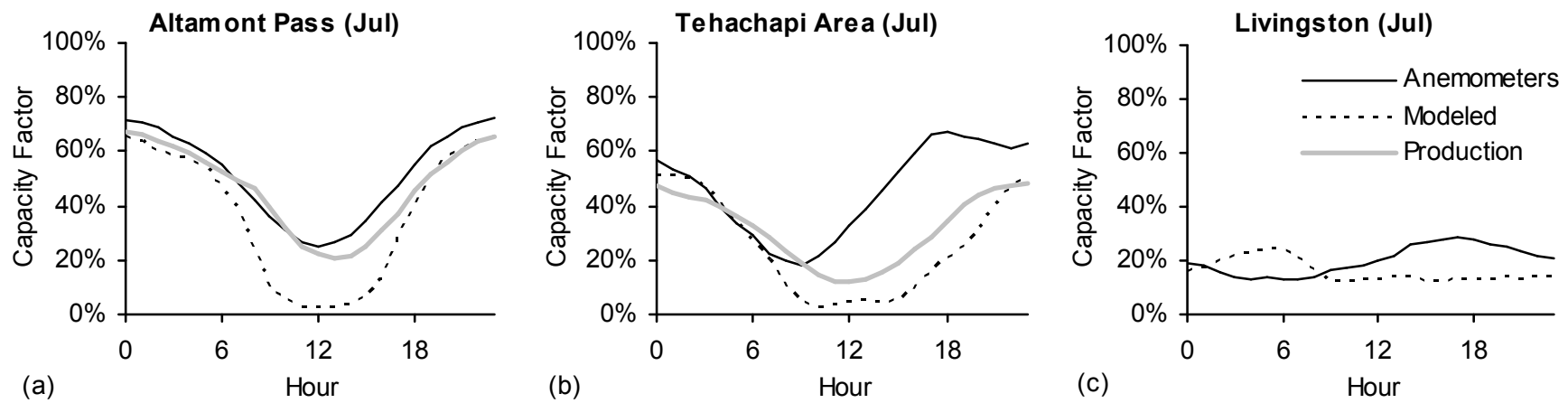

Fig. 2. Summer diurnal power production for three resource areas, from anemometers and modeled data at the same grid cell, and production turbines in the same region.

all local sites, based on their value to the region as a whole; however, the value of power could be somewhat different if it were calculated using more localized loads or market prices.

We also note that the results of this study are not guaranteed to be applicable over the long term, because they are based on wind, load and market price data which are only available for a limited number of years. In particular, anemometer and production data are not available for a long historical period, nor for years which match recent load and price data.

\section{RESULTS}

In this section, we first discuss the temporal pattern of winds in the study regions and differences in these patterns as reported by our three datasets. We then discuss the effect of wind timing on the value of wind power, drawing particular attention to findings that are consistent among all three datasets.

\section{A. Seasonal and Diurnal Timing of Winds}

In coastal passes in both California and the Northwest, all three of our datasets show peak winds during the summer, driven by a complex interaction of the sea breeze circulation, high pressure over the North Pacific, and a coastal subsidence inversion [38, 39]. Further inland, winds are more stormdriven, and wind speeds generally peak in the winter, according to all three datasets.

Winds throughout both regions have relatively little diurnal variation at any time of year, with the exception of summer winds in coastal passes. There, all three datasets show strongly night-peaking winds and daytime lulls (Fig. 2a,b).

There is some disagreement among the datasets about summer afternoon wind speeds, particularly in coastal passes. The modeled data show lower wind speeds than the anemometers on summer days in most coastal locations (Fig. 2a,b) and a few inland locations (Fig. 2c). The historical production data from operating wind projects are more similar to the anemometer data in some cases (Fig. 2a) and the modeled data in others (Fig. 2b).

California's electricity loads peak on summer afternoons, so accurate estimates of summer daytime wind speeds or power production at turbine hub heights are needed in order to cor- rectly estimate the value of power delivered to this state. Unfortunately, a number of factors could reduce the accuracy of estimates of these data in each of our datasets. Numerical weather models use limited resolution and mathematical complexity, which introduces some uncertainty into their wind speed estimates. On the other hand, our anemometer and historical production data come from relatively short towers during arbitrary time periods, so they may not reflect conditions at 70 meter elevation or over a long historical period as well as a numerical weather model. More discussion of these concerns can be found in [17].

Because none of our datasets can be identified as the most accurate estimate of prevailing wind conditions, in the sections that follow we emphasize findings that are common to all three datasets.

\section{B. Effects of Wind Timing in Each Resource Area}

We first assess the effects of wind timing in individual resource areas where anemometers were placed, as shown in Fig. 1. These may be the regions most likely to receive future wind power development. We show the effects of wind timing in each resource area using market data from both California and the Northwest, rather than assuming that all wind power is used in the same region where it is produced.

We calculated the effects of wind timing using historical electricity loads and historical wholesale market prices [17]. Variations in peak-hours capacity factor $\left(f_{c}\right)$ between sites are about seven times greater than the variations in wholesale market value $\left(f_{v}\right)$ shown here. Despite this difference in magnitude, the two measures generally identify the same sites as having well-timed or poorly-timed winds.

Fig. 3 shows the effect of wind timing on the value of wind power from each of the resource areas, when considering historical Northwestern wholesale power prices. The circles indicate the median effect among all anemometer sites in each resource area. The squares indicate the median effect found using modeled data for the same sites. For the Altamont, Tehachapi and San Gorgonio resource areas, we also show the effects calculated using the total output from all wind farms in each resource area. There is good agreement between the anemometer and modeled datasets when assessing the value of 


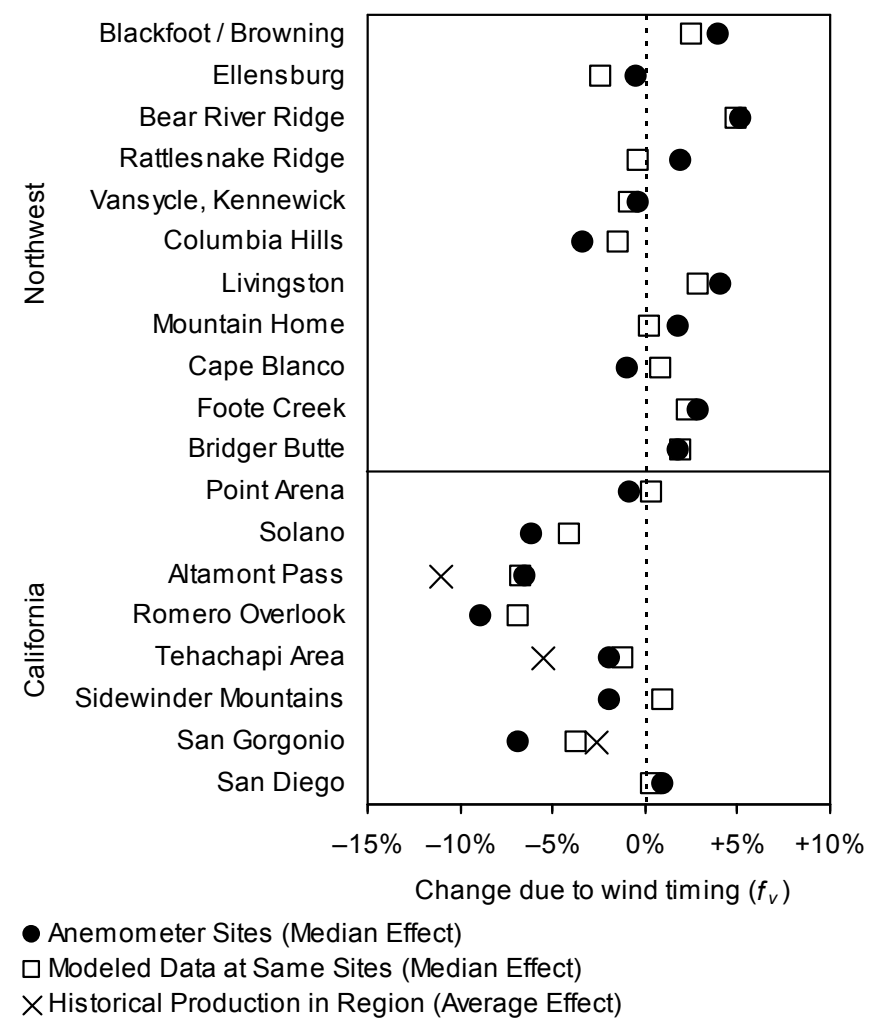

Fig. 3. Median effect of wind timing on wholesale market value at anemometer sites in each resource area, based on historical Northwestern prices.

power using the Northwest's wholesale prices (which peak in the winter). Seven or eight out of eleven Northwestern resource areas appear to be at least somewhat positively matched to the Northwest's wholesale prices, while only 1-3 of the eight California resource areas show a positive match, which is weak at best.

Fig. 4 shows the effect of wind timing when using California's historical wholesale prices, which peak strongly on summer afternoons. As was discussed in section III.A, anemometers in coastal passes and some inland sites show higher winds at these times than the modeled data. Consequently, the anemometer data give more positive estimates of the effect of wind timing in these locations.

According to the anemometer data shown in Fig. 4, about a third of the Northwestern resource areas and half of the California resource areas are positively matched to California's summer-afternoon-peaking historical prices. However, modeled data at the same locations suggest that only a quarter of the Northwestern resource areas and no California areas are positively matched to California's historical prices. Where available, the actual historical power production data yield results that are intermediate between those found using the other two datasets.

One might expect many of the California resource areas to be positively matched to the state's power markets, based on the fact that winds at these sites peak in the summer. However, both the modeled and anemometer data suggest that daytime lulls reverse this positive match, so that the value of power at these sites is roughly equal to or less than that of a flat block of

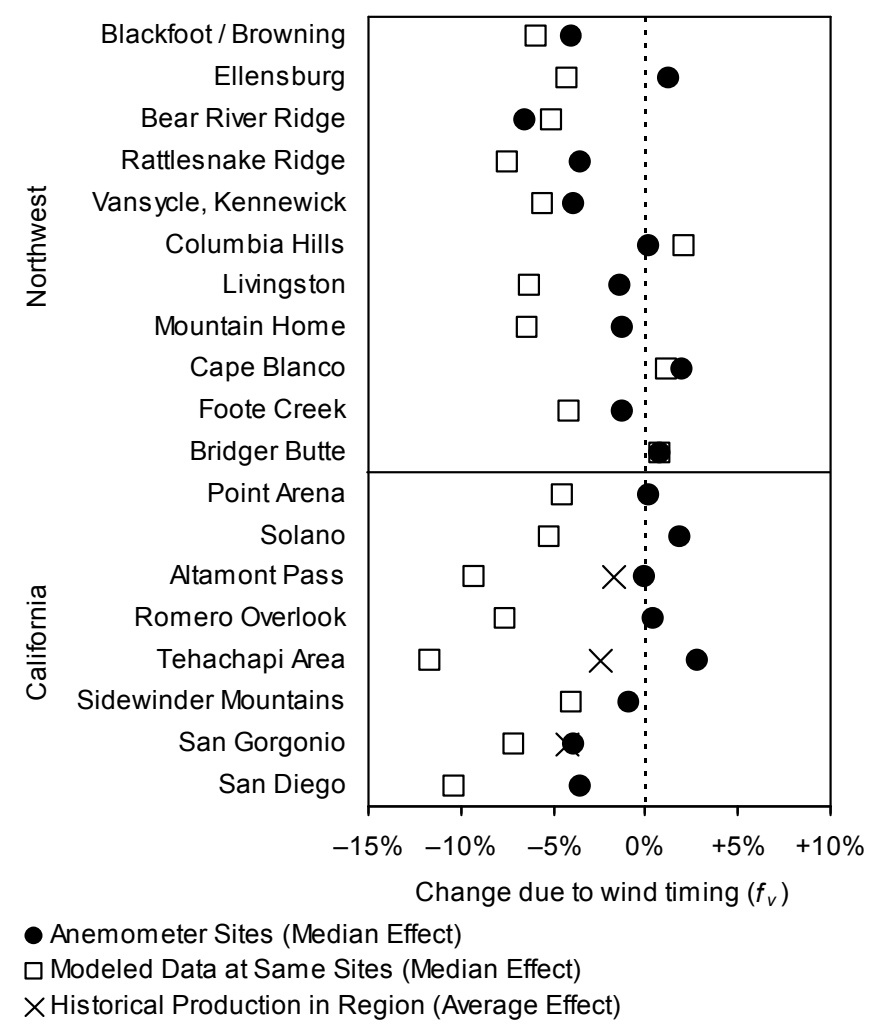

Fig. 4. Median effect of wind timing on wholesale market value at anemometer sites in each resource area, based on historical California prices.

power.

\section{Range of Results Among All Anemometer Sites}

We next consider the range of the effect of wind timing among all anemometer sites in all resource areas. In this section, we assume that California wind power is used in California, and Northwestern wind power is used in the Northwest.

Fig. 5 shows the range we found for $f_{c}$ and $f_{v}$ when using the available anemometer measurements in each region, and when using modeled data for the grid cells at the same locations as the anemometers. Central bars show the median value of $f_{c}$ or $f_{v}$ among all anemometer sites in each region, boxes show the interquartile range, and whiskers show the range between the 10th and 90th percentiles. These locations do not cover all possible wind sites in the state (see next section). However, anemometers in our dataset are generally concentrated in the most promising areas for wind development, so the results found at these locations may be representative of the effects of wind timing among all the areas where wind farms are likely to be built.

In the Northwest, using either the anemometer or modeled data, wind resources at the anemometer sites appear to be about neutrally matched to historically winter-peaking electrical loads and wholesale market prices.

In California, the anemometer data suggest that wind timing has a neutral effect or slightly raises the value of power, while the modeled data suggest that wind timing generally reduces the value of power at the same locations.

Despite this disagreement, the two datasets generally agree 


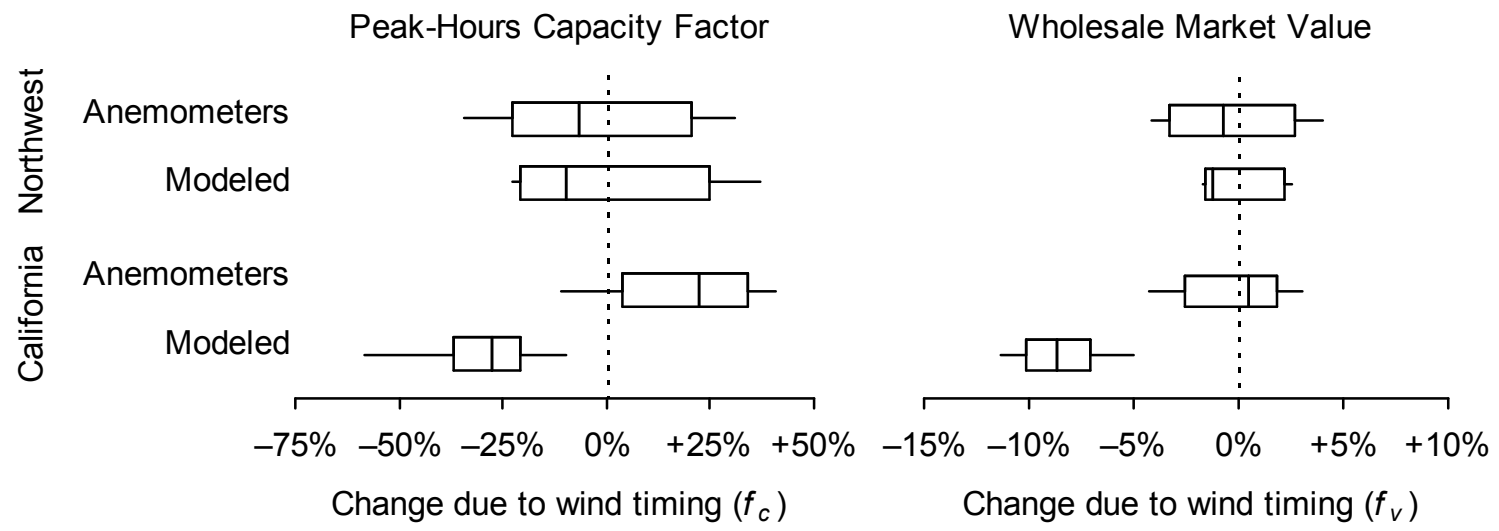

Fig. 5. Effects of wind timing on the value of power, derived from anemometer measurements and from modeled data for the same sites (10th, 25th, 50th, 75th, and 90th percentiles). Northwestern prices and loads were used for Northwestern sites, and California prices and loads were used for California sites. The anemometer and modeled datasets yield similar median values for the Northwestern sites but disagree for California. The two datasets show similar ranges between the best and worst-timed sites in each region: about $50 \%$ for the peak-hours capacity factor and about $8 \%$ for the market value.

Peak-Hours Capacity Factor

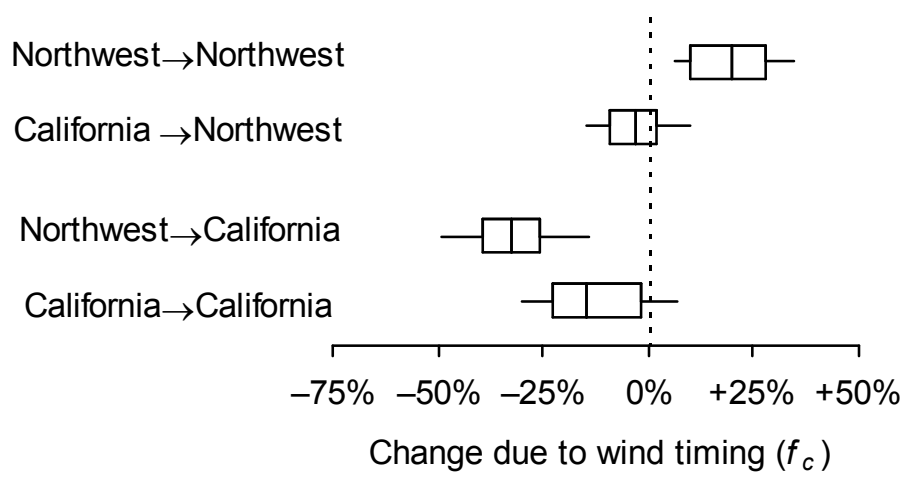

Wholesale Market Value

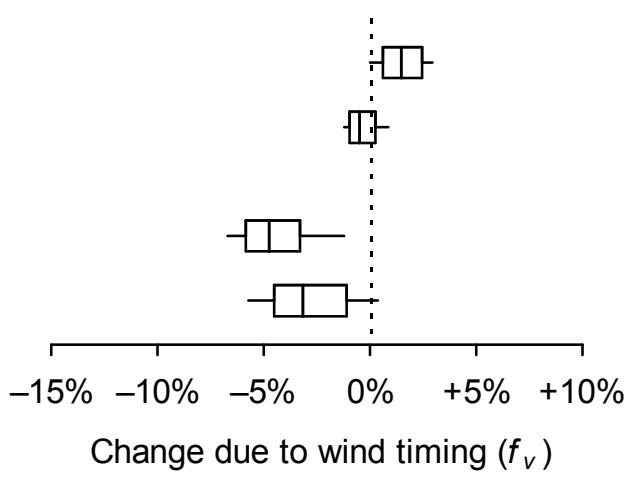

Fig. 6. Effect of wind timing on peak-hours capacity factor and annual market value at all Class $4+$ grid cells, based on modeled data (10th, 25th, 50th, 75th, and 90th percentiles). Arrows indicate the region where wind power is generated and where it is used.

on the range of the effect of wind timing. According to either dataset, well- and poorly-timed wind sites with the same annual average power production could have up to a 50 percent difference in peak-hours capacity factor $\left(f_{c}\right)$ or about an 8 percent difference in annual market value $\left(f_{v}\right)$. These ranges are similar to the variation between different resource areas.

To put this degree of variation in perspective, we note that a wind site with poor wind timing and high Class 4 wind speeds $(7.9 \mathrm{~m} / \mathrm{s})$ would have about the same market value as a site with good wind timing and typical Class 4 wind speeds ( 7.5 $\mathrm{m} / \mathrm{s}$ ). Consequently, the timing of wind is likely to be less important than the annual average wind speed in determining the wholesale market value of power from a new wind site. However, the timing of wind could have a substantial effect on the capacity value of a wind site: a well timed Class 4 site with wind speeds of $7.5 \mathrm{~m} / \mathrm{s}$ could have the same peak-hours capacity factor as a poorly timed Class 7 site with wind speeds averaging $12 \mathrm{~m} / \mathrm{s}$.

\section{Range of Results Among All Modeled Grid Cells}

We next consider the effect of wind timing at all modeled grid cells in California and the Northwest with annual average winds equivalent to a Class 4 or better wind site (average wind speed $>7.3 \mathrm{~m} / \mathrm{s}$ ). These locations have wind speeds that are usually considered economically viable for wind power development, so this allows us to assess the effect of wind timing among all possible wind sites, rather than just the ones where anemometers have been placed in the past. However, it should be noted that these results include many locations that are inaccessible or otherwise unsuitable for wind farm development (e.g., steep mountain ridges or national parks).

Fig. 6 shows the results of this analysis, with wind power used locally or exported to the neighboring region. According to the modeled data, temporal wind patterns could have a large effect on the average power output during hours of peak electricity demand, and a smaller but not insignificant effect on the annual wholesale market value of wind power.

The modeled data indicate that the best- and worst-timed of the windy Northwestern grid cells have capacity-factors during the Northwest's peak load hours that range from 6 to 34 percent above their annual average capacity factors (at the 10th and 90th percentiles), with a median of 20 percent above. Windy locations in California have capacity factors during 
California's peak load hours that range from 7 percent above to 30 percent below their annual average capacity factors, with a median of 15 percent below. According to the modeled data, loads in each region are best served by local wind power, rather than imports from the neighboring region. This differs from the anemometer results shown in Fig. 4, which indicate that Northwestern and California winds are about equally matched to California markets.

According to the modeled data, the worst-timed Northwestern sites have a wholesale market value approximately equal to what would be obtained if their power output was completely uncorrelated with electricity demand, while the besttimed sites have a market value about 3 percent more than this, based on the Northwest's historical prices. Windy California sites match historical California prices about 0-6 percent worse than a flat block of power. Again, the modeled data indicate that each region is better served by local rather than imported wind power.

Fig. 7 shows the geographic distribution of the effect of wind timing at all Class 4+ grid cells, according to the modeled dataset, when using Northwestern wind power with the Northwest's historical prices or California wind power with California's historical prices. Wind timing appears to have a neutral or positive effect at most Northwestern high-wind locations. In California, wind timing appears to improve the value of power from the northernmost coast, but reduces the value of power from high-wind locations elsewhere in the state.

It is tempting to conclude from this map that California wind sites have inherently poor wind timing, while Northwestern sites have good timing. However, Fig. 6 indicates that winds throughout both regions are generally poorly matched to California loads and markets, and neutrally or positively matched to Northwestern loads and markets. This suggests that much of the difference between the two regions may be due to the timing of electricity loads and markets, rather than the timing of winds.

Compared to the modeled data in Figs. 3-5, Figs. 6-7 show a more neutral match between California winds and either California or Northwestern electricity demand. This may be because Figs. 6-7 include all possible Class $4+$ sites, providing more diversity in wind timing than the anemometer sites shown in Figs. 3-5. Figs. 6-7 also show Northwestern wind sites as better matched to Northwestern loads and markets than Figs. 3-5 suggest. This may be because Figs. 6-7 include winter-peaking mountain sites, where anemometers have not been placed and wind resource development is unlikely.

\section{CONCLUSION}

Although the wind datasets used for this analysis have some inconsistencies, there are also areas of agreement, from which we are able to reach several important conclusions about the effect of wind timing on the value of wind power.

Temporal patterns have a moderate impact on the wholesale market value of wind power. According to both the ane-
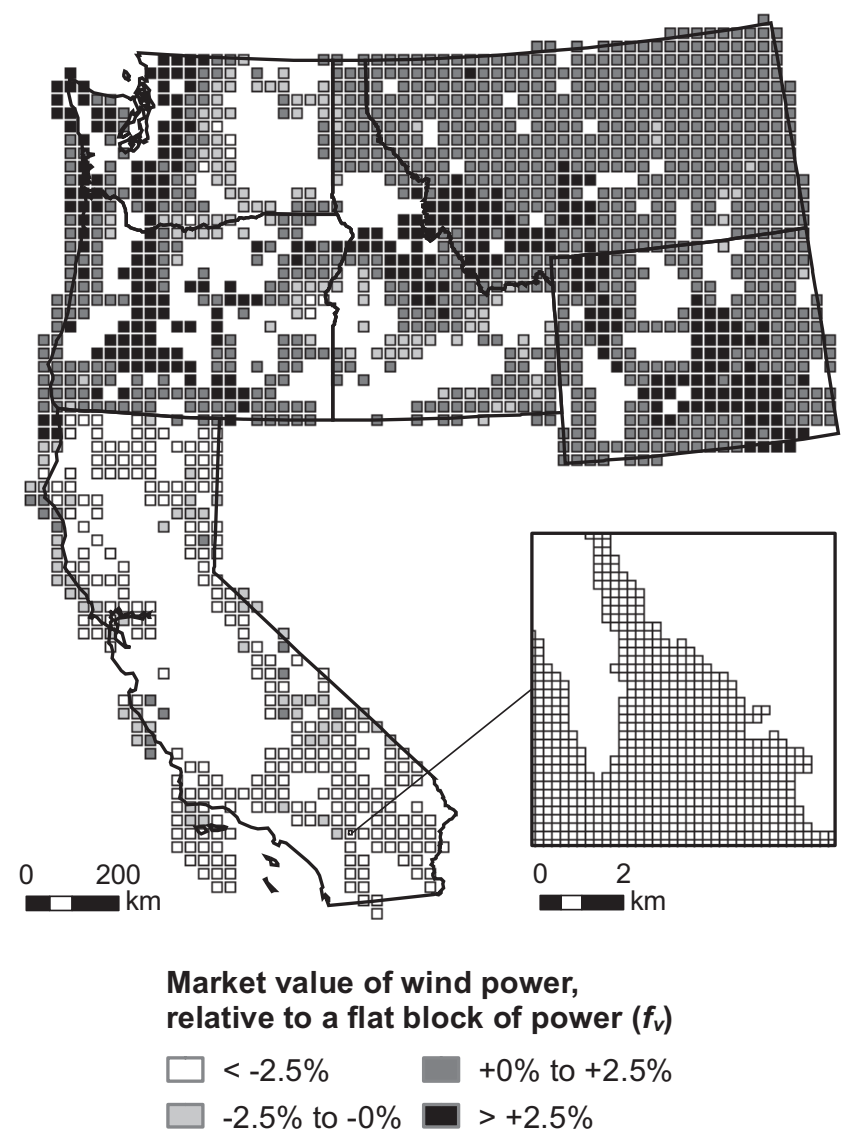

Fig. 7. Percentage change in market value of power due to the timing of wind at Class 4+ grid cells, based on modeled data. Wind in most California high-wind locations is poorly matched to California power markets, but Northwestern wind is better matched to Northwestern markets. (Inset shows the resolution of the underlying modeled data.)

mometer and modeled datasets, the best-timed wind power sites have a wholesale market value that is up to 4 percent higher than the average market price, while the worst-timed sites have a market value that is up to 11 percent below the average market price. This is a relatively narrow range, and suggests that the timing of wind is not likely to severely degrade the market value of wind power.

Temporal patterns have a substantial impact on the capacity factor during peak hours. The best-timed wind sites could produce as much as $30-40$ percent more power during the top 10 percent of peak load hours than they do on average during the year, while the worst timed sites may produce $30-60$ percent less power during these hours. It would be valuable to develop better estimates of the effective load-carrying capacity (ELCC) at different wind sites, in order to better assess the effect of wind timing on the capacity credit for wind farms.

Northwestern markets appear to be well served by Northwestern wind and poorly served by California wind; results are less clear for California markets. Both the modeled data and the anemometer data indicate that many Northwestern wind sites are reasonably well-matched to the Northwest's historically winter-peaking wholesale electricity prices and loads, while most California sites are poorly matched to these prices and loads. However, the modeled data indicate that 
most California and Northwestern wind sites are poorly matched to California's summer-afternoon-peaking prices and loads, while the anemometer data suggest that many of these same sites are more neutrally matched to California's wholesale prices and loads.

Modeled and anemometer data agree about wind speeds in most times and places, but disagree about California's summer afternoon wind speeds: The modeled data indicate that wind speeds at sites in California's coastal mountains and some Northwestern locations dip deeply during summer days and stay low through much of the afternoon. In contrast, the anemometer data indicate that winds at these sites begin to rise during the afternoon and are relatively strong when power is needed most. At other times and locations, the two datasets show good agreement. This disagreement may be due in part to time-varying wind shear between the anemometer heights $(20-25 \mathrm{~m})$ and the model reference height $(50 \mathrm{~m}$ or $70 \mathrm{~m})$, but may also be due to modeling errors or data collection inconsistencies. These findings suggest that it is reasonable to use TrueWind's modeled data to assess the effect of temporal patterns in wind speeds, especially when the value of electricity does not peak sharply in the summer. However, more data from tall anemometer towers or operational wind farms are needed to resolve differences between the datasets for summer afternoons.

\section{ACKNOWLEDGMENT}

The authors thank Steve Lindenberg, Larry Mansueti, Jack Cadogan and Alejandro Moreno, all of the U.S. Department of Energy, for their support of this work. For reviewing drafts of this manuscript and/or providing critical data or insights that made this work possible, we also thank Michael Brower, Michael Milligan, Marc Schwartz, Dennis Elliott, Mark Bolinger, George N. Scott, Stel N. Walker, Heather Rhoads-Weaver, Donna Heimiller, Ray George, Dora Yen Nakafuji, Elliot Mainzer, Orville J. Blumhardt, Kristina E. Rohe, Jeff King, Joel Klein, Ron Nierenberg, Severin Borenstein, Case van Dam, and Kevin Jackson. Any remaining errors or omissions are our own.

\section{REFERENCES}

[1] S. M. J. Baban and T. Parry, "Developing and applying a GIS-assisted approach to locating wind farms in the UK," Renewable Energy, vol. 24, pp. 59-71, 2001.

[2] S. H. Jangamshetti and V. G. Rau, "Optimum siting of wind turbine generators," IEEE Transactions on Energy Conversion, vol. 16, pp. 813, 2001.

[3] S. Roy, "Market constrained optimal planning for wind energy conversion systems over multiple installation sites," IEEE Transactions on Energy Conversion, vol. 17, pp. 124-129, 2002.

[4] M. Brower, J. W. Zack, B. Bailey, M. N. Schwartz, and D. L. Elliott, "Mesoscale modeling as a tool for wind resource assessment and mapping," presented at 14th Conference on Applied Climatology, Boston, MA, 2004.

[5] J. Nielsen, S. Innis, L. K. Pollock, H. Rhoads-Weaver, and A. Shutak, Renewable Energy Atlas of the West. Boulder, Colorado: Land and Water Fund of the Rockies, 2002.
[6] M. N. Schwartz, "Wind Resource Estimation and Mapping at the National Renewable Energy Laboratory," National Renewable Energy Laboratory, Golden, Colorado NREL/CP-500-26245, 1999.

[7] S. Kennedy and P. Rogers, "A Probabilistic Model for Simulating LongTerm Wind-Power Output," Wind Engineering, vol. 27, pp. 167-181, 2003.

[8] T. Burton, D. Sharpe, N. Jenkins, and E. Bossanyi, Wind Energy Handbook: John Wiley \& Sons, 2001.

[9] J. Carlin, "A theoretical model for estimating the capacity credit of wind power in the presence of correlation between wind speed and electricity demand," Solar Energy, vol. 31, pp. 511-515, 1983.

[10] O. Sezgen, C. Marnay, and S. Bretz, "Wind Generation in the Future Competitive California Power Market," Lawrence Berkeley National Laboratory, Berkeley, CA LBNL-41134, March 1998.

[11] H. Man Bae and M. D. Devine, "Optimization models for the economic design of wind power systems," Solar Energy, vol. 20, pp. 469-481, 1978.

[12] E. Kahn, Electric Utility Planning and Regulation. Washington, DC: American Council for an Energy-Efficient Economy, 1991.

[13] B. Kirby, M. Milligan, Y. Makarov, D. Hawkins, K. Jackson, and H. Shiu, "California Renewables Portfolio Standard Renewable Generation Integration Cost Analysis Phase I: One Year Analysis of Existing Resources," California Energy Commission, Berkeley, CA 500-03-108C, December 2003.

[14] M. Milligan, "Modeling Utility-Scale Wind Power Plants Part 2: Capacity Credit," National Renewable Energy Laboratory, Golden, Colorado NREL/TP-500-29701, 2002.

[15] A. J. M. van Wijk, N. Halberg, and W. C. Turkenburg, "Capacity credit of wind power in the Netherlands," Electric Power Systems Research, vol. 23, pp. 189-200, 1992.

[16] S. E. Fleten, K. M. Maribu, and I. Wangensteen, "Optimal investment strategies in decentralized renewable power generation under uncertainty," Energy, vol. In Press, Corrected Proof.

[17] M. Fripp and R. Wiser, "Analyzing the Effects of Temporal Wind Patterns on the Value of Wind-Generated Electricity at Different Sites in California and the Northwest," Lawrence Berkeley National Laboratory Report, Berkeley, CA LBNL-60152, June 2006.

[18] M. Brower, "New Wind Energy Resource Maps of California," California Energy Commission, Sacramento November 2002.

[19] M. Brower, "Wind Resource Maps of the Northwest and Wyoming," Northwest Cooperative Development Center Agreement \# NWCDC2001-01 and Agreement \# NWCDC-2001-02, October 2002.

[20] G. Scott, National Renewable Energy Laboratory, private communication, October, 2003.

[21] S. Walker, Energy Resources Research Laboratory, Oregon State University, private communication, March 12, 2004.

[22] M. Milligan, National Renewable Energy Laboratory, private communication, November 7, 2003.

[23] AWEA, "Wind Energy Projects in the U.S.," American Wind Energy Association, Washington, DC, on-line database, http://www.awea.org/projects/, Last Updated: December 31 2006, Accessed: April 22007.

[24] M. Milligan, National Renewable Energy Laboratory, private communication, March 12, 2004.

[25] WECC, "WECC 2006 Power Supply Assessment," Western Electricity Coordinating Council, Salt Lake City, UT May 92006.

[26] M. Milligan and K. Porter, "Determining the Capacity Value of Wind: A Survey of Methods and Implementation," presented at WINDPOWER 2005, Denver, Colorado, 2005.

[27] B. Kirby, M. Milligan, Y. Makarov, D. Hawkins, J. Lovekin, K. Jackson, and H. Shiu, "California Renewables Portfolio Standard Renewable Generation Integration Cost Analysis Phase III: Recommendations For Implementation," California Energy Commission, Sacramento, CA P500-04-054, July 2004.

[28] GE Energy, "The Effects of Integrating Wind Power on Transmission System Planning, Reliability, and Operations: Report on Phase 2," New York State Energy Research and Development Authority, Albany, NY March 2005.

[29] EnerNex Corporation, "Final Report - 2006 Minnesota Wind Integration Study, Volume I," The Minnesota Public Utilities Commission, Saint Paul, MN November 302006. 
[30] CPUC, "Opinion on Resource Adequacy Requirements," California Public Utilities Commission, San Francisco, CA Decision 05-10-042, October 272005.

[31] M. Milligan and B. Parsons, "A comparison and case study of capacity credit algorithms for intermittent generators," presented at Solar '97, Washington, DC, 1997.

[32] FERC, "Form 714 Data," Federal Energy Regulatory Commission, Washington, DC, http://www.ferc.gov/docs-filing/eforms/form714/data.asp, Last Updated: 2005, Accessed: September 292005.

[33] E. DeMeo, W. Grant, M. Milligan, and M. Schuerger, "Wind Plant Integration: Costs, Status, and Issues," IEEE Power \& Energy, vol. 3, pp. 38-46, 2005.

[34] B. Parsons, M. Milligan, J. C. Smith, E. DeMeo, B. Oakleaf, K. Wolf, M. Schuerger, R. Zavadil, M. Ahlstrom, and D. Y. Nakafuji, "Grid Impacts of Wind Power Variability: Recent Assessments from a Variety of Utilities in the United States," presented at European Wind Energy Conference, Athens, Greece, 2006.

[35] J. Smith, E. DeMeo, B. Parsons, and M. Milligan, "Wind Power Impacts on Electric-Power-System Operating Costs: Summary and Perspective on Work to Date " presented at Global WINDPOWER Conference, Chicago, IL, 2004.

[36] B. Parsons, M. Milligan, B. Zavadil, D. Brooks, B. Kirby, K. Dragoon, and J. Caldwell, "Grid Impacts of Wind Power: A Summary of Recent Studies in the United States " presented at European Wind Energy Conference and Exhibition, Madrid, Spain, 2003.

[37] BPA, Bonneville Power Association, private communication, October 21, 2005.

[38] L. L. Zaremba and J. J. Carroll, "Summer Wind Flow Regimes over the Sacramento Valley," Journal of Applied Meteorology, vol. 38, pp. 1463-1473, 1999.

[39] CEC, California Wind Atlas. Sacramento, CA: California Energy Commission, 1985.

Matthias Fripp holds an M.S. from the Energy and Resources Group, University of California, Berkeley (May 2003), and a B.A. in environmental studies from Lewis \& Clark College, Portland, Oregon.

$\mathrm{He}$ is currently a Ph.D. candidate in the Energy and Resources Group, studying the effects of intermittent renewable power sources on the reliability and cost of the electric power system. While performing the analysis reported here, he was a research assistant in the Electricity Markets and Policy Group at Lawrence Berkeley National Laboratory, Berkeley, California. Previous research includes characterizing electronic defects in silicon used for solar cells (U.C. Berkeley/LBNL); modeling climate change mitigation business opportunities (Trexler and Associates, Portland, Ore.); and analyzing learning effects in the wind and solar power industries (Lewis \& Clark College, Portland, Ore.).

Mr. Fripp is a member of the International Association for Energy Economics / USAEE. He is currently supported by a Science To Achieve Results (STAR) Graduate Fellowship from the U.S. Environmental Protection Agency.

Ryan H. Wiser received a B.S. in Civil Engineering from Stanford University and holds an M.S. and Ph.D. in Energy and Resources from the University of California, Berkeley.

$\mathrm{He}$ is a scientist in the Electricity Markets and Policy Group at Lawrence Berkeley National Laboratory. He leads research in the planning, design, and evaluation of renewable energy policies, and on the costs, benefits, and market potential of renewable electricity sources. His recent analytic work has included studies on the economics of wind power; the treatment of renewable energy in integrated resource planning; the cost of state-level renewables portfolio standards; trends in solar costs in California; state policy support for solar in the new home construction market; the risk mitigation value of renewable electricity; and customer surveys of willingness to pay for renewable generation. Dr. Wiser regularly advises and consults with state and federal agencies in the design and evaluation of renewable energy policies; is an advisor to the Energy Foundation's China Sustainable Energy Program; and is on the Corporate Advisory Board of Mineral Acquisition Partners. Prior to his employment at Berkeley Lab, Dr. Wiser worked for Hansen, McOuat, and Hamrin, Inc., the Bechtel Corporation, and the AES Corporation. 